\title{
BRAF mutation in thyroid cancer
}

\author{
M Xing
}

Division of Endocrinology and Metabolism, Department of Medicine, Johns Hopkins University School of Medicine, $1830 \mathrm{E}$. Monument St/Suite 333 Baltimore, MD 21287, USA

(Requests for offprints should be addressed to M Xing; Email: mxing1@jhmi.edu)

\begin{abstract}
Genetic alteration is the driving force for thyroid tumorigenesis and progression, based upon which novel approaches to the management of thyroid cancer can be developed. A recent important genetic finding in thyroid cancer is the oncogenic T1799A transversion mutation of BRAF (the gene for the B-type Raf kinase, BRAF). Since the initial report of this mutation in thyroid cancer 2 years ago, rapid advancements have been made. BRAF mutation is the most common genetic alteration in thyroid cancer, occurring in about $45 \%$ of sporadic papillary thyroid cancers (PTCs), particularly in the relatively aggressive subtypes, such as the tall-cell PTC. This mutation is mutually exclusive with other common genetic alterations, supporting its independent oncogenic role, as demonstrated by transgenic mouse studies that showed BRAF mutation-initiated development of PTC and its transition to anaplastic thyroid cancer. BRAF mutation is mutually exclusive with $R E T / P T C$ rearrangement, and also displays a reciprocal age association with this common genetic alteration in thyroid cancer. The T1799A BRAF mutation occurs exclusively in PTC and PTC-derived anaplastic thyroid cancer and is a specific diagnostic marker for this cancer when identified in cytological and histological specimens. This mutation is associated with a poorer clinicopathological outcome and is a novel independent molecular prognostic marker in the risk evaluation of thyroid cancer. Moreover, preclinical and clinical evaluations of the therapeutic value of novel specific mitogen-activated protein kinase pathway inhibitors in thyroid cancer are anticipated. This newly discovered $B R A F$ mutation may prove to have an important impact on thyroid cancer in the clinic.
\end{abstract}

Endocrine-Related Cancer (2005) 12 245-262

\section{Introduction}

Thyroid cancer is the most common endocrine malignancy. It can be classified histologically into follicular epithelial cell-derived papillary thyroid cancer (PTC), follicular thyroid cancer (FTC), anaplastic thyroid cancer (ATC), and para-follicular C-cellderived medullary thyroid cancer (MTC), which account for approximately $80,15,2$, and $3 \%$ of all thyroid malignancies, respectively (Hundahl et al. 1998). Thyroid cancer harbors several highly prevalent genetic alterations, some of which are seen only in this cancer. The classical oncogenic genetic alterations commonly seen in thyroid cancer include Ras mutations (Fagin 2002, Bongarzone \& Pierotti 2003), RET/ $P T C$ rearrangements (Nikiforov 2002, Santoro et al. 2002, Tallini 2002), and $P A X 8$-peroxisome proliferator-activated receptor $\gamma(P P A R \gamma)$ fusion oncogene
(Kroll et al. 2000, McIver et al. 2004). Various activating Ras mutations, widely seen in other cancers as well, occur mainly in FTC and the follicular variant of PTC (Vasko et al. 2003, Zhu et al. 2003). RET/PTC rearrangement represents a recombination of the promoter and $\mathrm{N}$-terminal domain of a partner gene with the C-terminal region of the RET gene, resulting in a chimeric oncogene with a protein product containing a constitutively activated RET tyrosine kinase. At lease 10 types of $R E T / P T C$ rearrangement have been identified, which differ by their $5^{\prime}$ partner genes, with $R E T / P T C 1, R E T / P T C 2$, and RET/PTC3 being the most common and occurring mainly in PTC and some benign adenomas. The PAX8-PPAR $\gamma$ occurs both in FTC and benign thyroid adenoma (Cheung et al. 2003, Sahin et al. 2005). The recently discovered activating mutation in $B R A F$ (the gene for the B-type Raf kinase, BRAF), the focus of this review, represents 
the most common genetic alteration in thyroid cancer. The RET and other mutations responsible for the less common and histologically distinct MTC, which are derived from parafollicular cells, are reviewed elsewhere (Koper \& Lamberts 2000, Ichihara et al. 2004, Santoro et al. 2004). Most of the genetic alterations in thyroid cancer exert their oncogenic actions at least partially through the activation of the $\mathrm{RET} / \mathrm{PTC} \rightarrow \mathrm{Ras} \rightarrow \mathrm{Raf} \rightarrow$ mitogen-activated protein kinase (MAP kinase)/extracellular-signal-regulated kinase (ERK) kinase (MEK) $\rightarrow$ MAP kinase/ERK pathway (referred as the MAP kinase pathway hereafter). Activation of this pathway is a common and important mechanism in the genesis and progression of human cancers through upregulating cell division and proliferation. When constitutively activated, the MAP kinase pathway leads to tumorigenesis (Peyssonnaux \& Eychene 2001, Hilger et al. 2002).

The discovery of activating mutations of the gene for BRAF has expanded the array of the known genetic alterations that activate the MAP kinase pathway and underscores the importance of this pathway in human cancer (Davies et al. 2002). Among the three forms of Raf kinases, BRAF, with its gene located on chromosome 7, is the most potent activator of the MAK kinase pathway (Sithanandam et al. 1992, Mercer \& Pritchard 2003). BRAF-activating missense point mutations in the kinase domain are clustered in exons 11 and 15 of the gene and the T1799A transversion mutation accounts for more than $80 \%$ of all the $B R A F$ mutations (Davies et al. 2002). This mutation had been formerly called T1796A, based on the NCBI GenBank nucleotide sequence NM 004333, which missed a codon (three nucleotides) in exon 1 of the $B R A F$ gene. With the correct version of the NCBI GenBank nucleotide sequence NT 007914 available, this BRAF mutation is now designated T1799A (Kumar et al. 2003), the term used in this review. The T1799A mutation results in a V600E (formerly designated V599E) amino acid substitution in the protein product and subsequent constitutive activation of the BRAF kinase. The V600E mutation is thought to mimic phosphorylation in the activation segment of BRAF by inserting a negatively charged residue adjacent to an activating phosphorylation site at Ser599 (Davies et al. 2002). This is believed to cause the conversion of BRAF to a catalytically active form by disrupting the association of the activation segment with the ATP-binding P loop, which normally holds BRAF in an inactive confirmation (Dhillon \& Kolch 2004, Hubbard 2004, Wan et al. 2004). The oncogenic and transforming function of the mutated V600E BRAF has been well demonstrated (Davies et al. 2002).
Since its initial discovery, $B R A F$ mutations have now been reported in numerous types of human cancer with various frequencies (Garnett \& Marais 2004), being most prevalent in melanomas and nevi, present in 66 and $82 \%$ of these dermatologic lesion types, respectively (Davies et al. 2002, Pollock et al. 2003). Over the last 2 years, substantial work has also described $B R A F$ mutations in thyroid cancer, with a prevalence second only to that in melanoma. Discovery of this genetic alteration has created the opportunity to develop novel clinical strategies for the management of thyroid cancer. This review summarizes recent achievements in this exciting research area and highlights the clinical implications of this mutation in thyroid cancer.

\section{High prevalence, specificity and oncogenic role of the T1799A BRAF mutation in PTC}

Numerous studies have consistently shown a high prevalence of $B R A F$ mutation in thyroid cancer, ranging from 29 to $83 \%$ (Namba et al. 2003, Kim et al. 2004; more references are listed in Table 1). The $B R A F$ mutation found in thyroid cancer is almost exclusively the T1799A transversion mutation in exon 15. This mutation is a somatic mutation in sporadic thyroid cancers (Kimura et al. 2003, Xu et al. 2003) and was found not to be a germ-line mutation in a large series of familial PTCs (M. Xing, unpublished results). The only other $B R A F$ mutation reported in thyroid tumors was the K601E mutation found in two benign thyroid adenomas (Soares et al. 2003, Lima et al. 2004) and three follicular-variant PTCs (Trovisco et al. 2004). The mutations in exon 11 of the BRAF gene found in other human cancers were not found in thyroid cancer (Cohen et al. 2003, Fukushima et al. 2003, Kimura et al. 2003, Namba et al. 2003, Frattini et al. 2004, Perren et al. 2004, Puxeddu et al. 2004). A rare but interesting genetic alteration that can also cause constitutive activation of BRAF is the recently reported in vivo fusion of the $B R A F$ gene with $A K A P 9$ gene through a paracentric inversion of the long arm of chromosome 7. This results in a recombinant AKAP9$B R A F$ oncogene, which appears to occur in PTCs induced by radiation exposure and results in the loss of the autoinhibitory regulatory domains of BRAF and hence constitutive activation of the kinase (Ciampi et al. 2005, Fusco et al. 2005).

The present review is focused on the T1799A $B R A F$ mutation, and the term $B R A F$ mutation hereafter specifically refers to the T1799A $B R A F$ mutation. As 
Table 1 Frequency of the T1799A transversion BRAF mutation in sporadic adult thyroid tumors

\begin{tabular}{|c|c|c|c|c|c|c|}
\hline \multirow[b]{2}{*}{ Report } & \multicolumn{5}{|c|}{ Frequency (mutation/total (\%)) } & \multirow[b]{2}{*}{ Reference } \\
\hline & PTC & FTC & ATC & MTC & $\begin{array}{c}\text { Benign } \\
\text { neoplasm }\end{array}$ & \\
\hline 1 & 28/78 (36) & $0 / 10(0)$ & - & - & 0/26 (0) & Kimura et al. 2003 \\
\hline 2 & 24/35 (69) & $0 / 16(0)$ & - & 0/3 (0) & $0 / 20(0)$ & Cohen et al. 2003 \\
\hline 3 & $21 / 56(38)$ & - & - & - & $0 / 24(0)$ & Xu et al. 2003 \\
\hline 4 & $23 / 50(46)$ & $0 / 18(0)$ & - & - & $0 / 72(0)$ & Soares et al. 2003 \\
\hline 5 & $40 / 76(53)$ & $0 / 8(0)$ & $0 / 7(0)$ & 0/9 (0) & - & Fukushima et al. 2003 \\
\hline 6 & $49 / 170(29)$ & $0 / 11(0)$ & $2 / 6(33)$ & - & $0 / 20(0)$ & Namba et al. 2003 \\
\hline 7 & $45 / 119(38)$ & $0 / 32(0)$ & $3 / 29(10)$ & $0 / 13(0)$ & $0 / 111(0)$ & Nikiforova et al. 2003 \\
\hline 8 & $18 / 30(60)$ & $0 / 12(0)$ & - & - & $0 / 9(0)$ & Xing et al. 2004a \\
\hline 9 & $14 / 28(50)$ & $0 / 14(0)$ & $2 / 10(20)$ & $0 / 14(0)$ & $0 / 54(0)$ & Xing et al. $2004 b$ \\
\hline 10 & $8 / 16(0)$ & $0 / 6$ & - & - & $0 / 21(0)$ & Xing et al. $2004 c$ \\
\hline 11 & $45 / 124(36)$ & - & - & - & - & Trovisco et al. 2004 \\
\hline 12 & - & - & $8 / 16(50)$ & - & - & Begum et al. 2004 \\
\hline 13 & $58 / 70(83)$ & - & - & - & - & Kim et al. 2004 \\
\hline 14 & $30 / 82(37)$ & - & - & - & - & Nikiforova et al. 2004 \\
\hline 15 & 36/95 (38) & $0 / 2(0)$ & $2 / 2(100)$ & 0/1 (0) & $0 / 32(0)$ & Cohen et al. 2004 \\
\hline 16 & 19/60 (32) & - & - & - & - & Frattini et al. 2004 \\
\hline 17 & $18 / 56(32)$ & $0 / 5(0)$ & $0 / 4(0)$ & - & $0 / 1(0)$ & Fugazzola et al. 2004 \\
\hline 18 & $24 / 60(40)$ & $0 / 5(0)$ & $0 / 1(0)$ & - & $0 / 6(0)$ & Puxeddu et al. 2004 \\
\hline 19 & - & - & $6 / 17(35)$ & - & - & Soares et al. 2004 \\
\hline 20 & 97/232 (42) & - & - & - & - & Penko et al. 2004 \\
\hline 21 & 26/69 (38) & - & - & - & $0 / 27(0)$ & Salvatore et al. 2004 \\
\hline 22 & $13 / 46(28)$ & - & - & - & - & Sedliarou et al. 2004 \\
\hline 23 & $55 / 91(60)$ & $0 / 3(0)$ & - & - & $0 / 24(0)$ & Vasil'ev et al. 2004 \\
\hline 24 & - & - & - & & $0 / 40(0)$ & Krohn et al. 2004 \\
\hline 25 & - & - & - & - & $0 / 10(0)$ & Kimura et al. 2004 \\
\hline 26 & $7 / 15(47)$ & $0 / 7(0)$ & - & $0 / 24(0)$ & - & Perren et al. 2004 \\
\hline 27 & $37 / 72(51)$ & $0 / 8(0)$ & $0 / 2(0)$ & $0 / 1(0)$ & $0 / 45(0)$ & Hayashida et al. 2004 \\
\hline 28 & $38 / 61(62)$ & $0 / 8(0)$ & - & - & - & Porra et al. 2005 \\
\hline 29 & $37 / 65(57)$ & - & - & - & - & M Xing et al. unpublished results \\
\hline Overall & $810 / 1856(44)$ & $0 / 165(0)$ & 23/94 (24) & $0 / 65(0)$ & $0 / 542(0)$ & \\
\hline
\end{tabular}

shown in Table 1, in all the studies published to date $B R A F$ mutation has been found only in PTCs and some apparently PTC-derived ATCs, but not in FTCs, MTCs, or benign thyroid neoplasms (adenoma or hyperplasia). The $B R A F$ mutation-positive ATCs were likely derived from $B R A F$ mutation-positive PTCs as suggested by the co-existence of PTC and ATC components in the same tumor, which both harbored the BRAF mutation (Nikiforova et al. 2003, Begum et al. 2004, Cohen et al. 2004). As summarized in Table 1 , the pooled data on sporadic adult thyroid cancer patients from the 29 studies revealed an overall prevalence of $B R A F$ mutation of $44 \%(810 / 1856)$ in PTC and 24\% (23/94) in ATC. None of the 165 FTCs, 65 MTCs, or 542 benign neoplasms harbored the $B R A F$ mutation. This association of PTCs with the $B R A F$ mutation, demonstrated consistently in various studies with patients from different geographical and ethnic backgrounds, strongly supports a unique role of
$B R A F$ mutation in the pathogenesis of PTC. BRAF mutation is the most prevalent among the known common oncogenic genetic alterations in thyroid cancer, including the ras mutations, RET/PTC rearrangements, and $P A X 8-P P A R \gamma$ rearrangements. The high frequency and specificity of $B R A F$ mutation suggest that this mutation may play a fundamental role in the initiation of PTC tumorigenesis. This idea was supported by the presence of $B R A F$ mutation in micro PTC (Nikiforova et al. 2003, Sedliarou et al. 2004, Trovisco et al. 2004). The presence of BRAF mutation in both the differentiated PTC components and the undifferentiated components in ATC tumors suggest a role for $B R A F$ mutation in disease progression (from well-differentiated PTC to undifferentiated ATC; Nikiforova et al. 2003, Begum et al. 2004, Cohen et al. 2004). Consistent with this concept, a study by Sedliarou et al. (2004) showed that when welldifferentiated tumors contained less-differentiated 
Table 2 T1799A BRAF mutation in the common subtypes of PTC

\begin{tabular}{ccccl}
\hline & \multicolumn{3}{c}{ Frequency (mutation/total (\%)) } \\
\cline { 2 - 4 } Report & Conventional PTC & Follicular-variant PTC & Tall-cell PTC & \multicolumn{1}{c}{ Reference } \\
\hline 1 & $28 / 53(53)$ & $2 / 30(7)$ & $6 / 6(100)$ & Nikiforova et al. 2003 \\
2 & $28 / 42(67)$ & $6 / 51(12)$ & - & Cohen et al. 2004 \\
3 & $58 / 70(83)$ & - & - & Kim et al. 2004 \\
4 & $28 / 53(53)$ & $0 / 32(0)$ & $1 / 3(33)$ & Trovisco et al. 2004 \\
5 & - & - & $11 / 14(79)$ & Frattini et al. 2004 \\
6 & $18 / 47(38)$ & $0 / 6(0)$ & - & Fugazzola et al. 2004 \\
7 & $19 / 35(54)$ & - & - & Puxeddu et al. 2004 \\
8 & $16 / 35(45)$ & $2 / 9(22)$ & $5 / 9(55)$ & Salvatore et al. 2004 \\
9 & $36 / 52(69)$ & $8 / 25(32)$ & - & Porra et al. 2005 \\
10 & $15 / 24(63)$ & $21 / 175(12)$ & $37 / 48(77)$ & M Xing et al. unpublished results \\
Overall & $246 / 411(60)$ & &
\end{tabular}

components, the prevalence of $B R A F$ mutation was increased significantly. The $B R A F$ mutation is not the only driving force for the formation of ATC, as many ATC tumors do not harbor this mutation; this latter group of ATCs is likely derived from FTC, which is negative for BRAF mutation (Nikiforova et al. 2003, Cohen et al. 2004, Soares et al. 2004). The most convincing evidence to support a role of $B R A F$ mutation in the initiation and progression of PTC comes from the demonstration (Knauf et al. 2004) that the formation of PTC could be induced in transgenic mice in which expression of the V600E BRAF mutant was targeted to thyroid cells. PTC formed in this mouse model transitioned to more aggressive undifferentiated PTC, recapitulating the clinical findings on the association of $B R A F$ mutation with a poorer prognosis of PTC, as will be discussed below (Namba et al. 2003, Nikiforova et al. 2003, Kim et al. 2004; M. Xing et al. unpublished results).

PTC can be further classified into several histologically distinct subtypes, including the most widely accepted and commonly seen: conventional PTC, follicular-variant PTC, and tall-cell PTC (Chan 1990). The distribution of BRAF mutation in PTC shows a clear subtype-related pattern. As summarized in Table 2, from the nine reports that have provided data on PTC subtype distribution of $B R A F$ mutation, the prevalence of this mutation is highest in tall-cell PTC $(77 \%)$, second highest in conventional PTC $(60 \%)$, and lowest in follicular-variant PTC $(12 \%)$. As other subtypes of PTC are rare, BRAF mutation has not been generally studied in these thyroid cancers. The study by Trovisco et al. (2004) represents one attempt to examine $B R A F$ mutation in a relatively high number of uncommon subtypes of PTC. In this study, the authors found $B R A F$ mutation in six $(40 \%)$ of 15 oncocytic-variant PTCs and six (75\%) of eight
Warthin-like PTCs, but not in two diffuse sclerosing PTCs, one columnar cell variant PTC, five hyalinizing trabecular thyroid tumors, or in five mucoepidermoid thyroid tumors. As these are rare thyroid tumors, $B R A F$ mutation in these tumors has generally not been reported by other studies.

Different subtype compositions of PTC, when analyzed without subtype stratification in various reports, may partially explain the wide variation in the prevalence of $B R A F$ mutation reported by different authors. It should be pointed out that different observers may sometimes define the histological types of thyroid cancer differently (Franc 2003, Lloyd et al. 2004), which may affect the accuracy in reporting the tumor-subtype pattern of $B R A F$ mutation. However, the distribution pattern of $B R A F$ mutation among the three most common subtypes of PTC - conventional PTC, follicular-variant PTC, and tall-cell PTC - most likely represents a true phenomenon as these histological types of PTC can usually be defined with relative ease and the $B R A F$ mutation pattern described here has been consistently revealed in all the studies that reported PTC subtypes in the analysis of $B R A F$ mutation (Table 2). Therefore, BRAF mutation appears to play a major role in the tumorigenesis of tall-cell PTC and conventional PTC. This may explain some of the common features seen in these two subtypes of PTC, such as their high tendency to undergo lymph node metastasis. As tall-cell PTC and conventional PTC are more aggressive than follicularvariant PTC, and as tall-cell PTC is known to be particularly aggressive (Merino \& Monteagudo 1997, Akslen \& LiVolsi 2000, Prendiville et al. 2000), the order of tall-cell variant $>$ conventional variant $\gg$ follicular-variant PTC in the prevalence of $B R A F$ mutation is consistent with the idea that $B R A F$ mutation is a driving force behind thyroid cancer's 
aggressivity. This will become more evident in the discussion regarding the prognostic value of $B R A F$ mutation.

\section{Mutual exclusivity between BRAF mutation and other common genetic alterations in thyroid cancer}

Mutual exclusivity between $B R A F$ mutation and ras mutation was seen in several types of human cancer, including, for example, colorectal cancer (Rajagopalan et al. 2002), melanoma (Omholt et al. 2003), and ovarian cancer (Singer et al. 2003). Mutual exclusivity between these two mutations was also seen in thyroid cancer (Fukushima et al. 2003, Kimura et al. 2003, Soares et al. 2003, Frattini et al. 2004). These and other studies (Kumagai et al. 2004, Lima et al. 2004, Nikiforova et al. 2004, Vasil'ev et al. 2004) similarly showed mutual exclusivity between $B R A F$ mutation and $R E T / P T C$ rearrangements in thyroid cancer. In fact, no study showed more than one type of these three common genetic alterations in the same case of thyroid cancer, except one study showing the overlap of BRAF mutation with RET/PTC (Xu et al. 2003). In this study, however, immunohistocheminical staining was used to define the presence of RET/PTC using $\mathrm{C}$-terminal-specific antibodies. The results may therefore be non-specific as the antibodies used may not reliably discriminate between the rearranged and the wild-type RET proteins. Expression of the wild-type $R E T$ or $R E T$ proto-oncogene was previously demonstrated in PTC, particularly in PTC that lack the major $R E T / P T C$ rearrangements (Bunone et al. 2000). In general, the data on $B R A F$ mutation, ras mutation, and $R E T / P T C$ rearrangements in thyroid cancer support the idea that each of the three genetic alterations alone is sufficient to cause thyroid tumorigenesis. The mutual exclusivity among these common genetic alterations in thyroid tumor may not be surprising, though, as the signaling pathways of these activating genetic alterations share the common MAP kinase pathway, albeit at different steps. A single oncogenic alteration along this pathway is likely sufficient to drive thyroid cell transformation and tumorigenesis. The genetic data supporting $B R A F$ mutation as an independent oncogenic event for PTC tumorigenesis is consistent with the results from the transgenic mouse studies mentioned above (Knauf et al. 2004).

Like various genetic alterations, loss of expression of the pro-apoptotic tumor suppressor Ras-associated factor 1 (RASSF1) through an epigenetic alteration, gene methylation, is another important mechanism in the tumorigenesis of many human cancers (Pfeifer et al. 2002). The three splice variants (A, B, C) of RASSF1 all possess a Ras-association domain (Dammann et al. 2000). Ras has been shown to be able to use RASSF1 as a direct effector in the downstream signaling (Vos et al. 2000). Therefore, RASSF1 may function through a Ras-like signaling pathway. Promoter methylation of RASSF1A was frequently found in thyroid tumors (Schagdarsurengin et al. 2002, Xing et al. 2004a) and this methylation silenced the expression of RASSF1A gene in thyroid tumor cells (Schagdarsurengin et al. 2002). Therefore, aberrant methylation of RASSF1A may represent another important oncogenic mechanism in thyroid tumorigenesis. Intriguingly, aberrant methylation of RASSF1A was recently found to be mutually exclusive with $B R A F$ mutation in PTC (Xing et al. 2004a). High-level RASSF1A methylation occurred mostly in FTC (Xing et al. 2004a), similar to ras mutations that also occur frequently in FTC (Vasko et al. 2003). Among different PTC subtypes, ras mutations were highly prevalent in follicularvariant PTC, while $R E T / P T C$ rearrangements, like $B R A F$ mutation, were more prevalent in conventional PTC (Zhu et al. 2003) and tall cell-variant PTC (Basolo et al. 2002). Therefore, it appears that PTC subtypepredilections may partially account for the mutual exclusivity of these genetic and epigenetic alterations recently reported in thyroid cancer. In most of these studies, analysis of all PTC for genetic alterations was conducted without stratification of histological subtypes. To be certain about the mutual exclusivity of these common genetic alterations and their respective roles in thyroid tumorigenesis in each specific subtype of PTC, it would be necessary to examine all of these genetic and epigenetic alterations simultaneously in each of the specific subtypes of PTC.

$B R A F$ mutation and $R E T / P T C$ rearrangements may act at steps that are different but close in their shared oncogenic pathway, resulting in conventional PTC, whereas ras mutations and RASSF1A methylation may act at different but related steps along their shared oncogenic pathway resulting in FTC and follicularvariant PTC. Although thyroid tumorigenesis caused by these genetic and epigenetic alterations may all involve the MAP kinase pathway, each of these genetic and epigenetic alterations, particularly those that act in this pathway at a step proximal to Raf kinase, may involve additional signaling pathways. For example, the phosphoinositide 3-kinase/Akt pathway, which is known to also play an important role in thyroid tumorigenesis, can be activated by Ras (Gire et al. 2000, Cheng \& Meinkoth 2001) or RET/PTC (Kim et al. 2003, Miyagi et al. 2004). This may partially 
Table 3 Prevalence of BRAF mutation and RET/PTC rearrangements in PTC in radiation-exposed and non-exposed children

\begin{tabular}{|c|c|c|c|c|c|}
\hline \multirow[b]{3}{*}{ Report } & \multicolumn{4}{|c|}{ Prevalence (genetic event/total (\%)) } & \multirow[b]{3}{*}{ Reference } \\
\hline & \multicolumn{2}{|c|}{$B R A F$ mutation } & \multicolumn{2}{|c|}{$R E T / P T C$ rearrangements } & \\
\hline & Radiation-exposed & Non-exposed & Radiation-exposed & Non-exposed & \\
\hline 1 & - & - & 29/38 (76) & $11 / 17(65)$ & Nikiforov et al. 1997 \\
\hline 2 & - & - & - & $15 / 33(45)$ & Fenton et al. 2000 \\
\hline 3 & $4 / 34(12)$ & $1 / 17(6)$ & $14 / 34(41)$ & - & Lima et al. 2004 \\
\hline 4 & $2 / 55(4)$ & - & $32 / 55(58)$ & - & Nikiforova et al. 2004 \\
\hline 5 & $0 / 15(0)$ & $1 / 31(3)$ & $17 / 48(35)$ & - & Kumagai et al. 2004 \\
\hline 6 & - & $0 / 7(0)$ & - & $3 / 6(50)$ & Penko et al. 2004 \\
\hline 7 & $1 / 5(20)$ & - & - & - & Xing et al. 2004b \\
\hline Overall & $7 / 109(6)$ & $2 / 55$ (4) & $92 / 175(53)$ & $29 / 56(52)$ & \\
\hline
\end{tabular}

explain the distinct characteristics of different subtypes of thyroid cancer that harbor different genetic and epigenetic alterations.

\section{Reciprocal age-association of BRAF mutation and RET/PTC rearrangements}

It is well known that $R E T / P T C$ is particularly common in the pediatric PTC that occurred in the victims of the Chernobyl nuclear accident (Ito et al. 1994, Fugazzola et al. 1995, Klugbauer et al. 1995, Nikiforov et al. 1997). A similarly high prevalence of $R E T / P T C$ has also been found in non-radiation-exposed sporadic pediatric PTC (Nikiforov et al. 1997, Fenton et al. 2000, Penko et al. 2004). As BRAF mutation and $R E T / P T C$ are together responsible for the majority of conventional PTC, the most common subtype of PTC, and are mutually exclusive in adult sporadic PTC, their relationship in pediatric PTCs, particularly in those that occurred as a result of the Chernobyl nuclear accident, has drawn much interest (Kumagai et al. 2004, Lima et al. 2004, Nikiforova et al. 2004, Xing et al. 2004b). As summarized in Table 3, and consistent with previous reports (Ito et al. 1994, Fugazzola et al. 1995, Klugbauer et al. 1995, Nikiforov et al. 1997), these recent studies uniformly showed a high prevalence of $R E T / P T C$ in both radiation-exposed and sporadic pediatric populations. As may be expected from the mutual exclusivity of $R E T / P T C$ and $B R A F$ mutation observed in sporadic adult PTC and from the known high frequency of $R E T / P T C$ in radiationexposed PTC, the initial study on a small series of PTC from Chernobyl victims showed a low prevalence of BRAF mutation (Xing et al. 2004b). In several subsequent larger studies on Chernobyl victims, the prevalence of $B R A F$ mutation in PTC was found consistently to be low in this special population, ranging from 0 to $12 \%$ (Kumagai et al. 2004, Lima et al. 2004, Nikiforova et al. 2004). As in sporadic adult PTC patients, mutual exclusivity of $B R A F$ mutation and RET/PTC was also demonstrated consistently in this Chernobyl population. It would be interesting to know, in a large series, how frequent the recently discovered radiation-sensitive recombinant AKAP9-BRAF oncogene (Ciampi et al. 2005, Fusco et al. 2005) would truly be and whether it, like the $B R A F$ mutation, is mutually exclusive with $R E T / P T C$ in Chernobyl- or radiation-related PTCs.

Interestingly, the study by Lima et al. (2004) on Chernobyl victims showed that the average age of the children at the time of radiation exposure was much higher for the group with $B R A F$ mutation than the group with $R E T / P T C$. In the study by Kumagai et al. (2004), when the Chernobyl radiation-exposed children were divided into two age groups, none $(0 \%)$ of the 15 cases in the group at or younger than 15 years harbored the BRAF mutation, whereas eight $(24 \%)$ of the 33 cases in the group older than 15 years harbored this mutation. Several of these studies (Kumagai et al. 2004, Lima et al. 2004, Penko et al. 2004) also showed the mutual exclusivity between $R E T / P T C$ and BRAF mutation and a low prevalence of the latter (ranging from 0 to $6 \%$ ) in non-radiationexposed sporadic PTC in the pediatric population. From these recent studies, the overall prevalence of $B R A F$ mutation for radiation-exposed and nonexposed pediatric PTC is 6 and $4 \%$, respectively, and the overall prevalence of $R E T / P T C$ rearrangements for radiation-exposed and sporadic pediatric PTC is 53 and $52 \%$, respectively (Table 3 ). The adult PTC patients included in some of these studies (Nikiforova et al. 2004, Xing et al. 2004b) showed uniformly a low prevalence of $R E T / P T C$ and a high prevalence of $B R A F$ mutation regardless of their history of radiation exposure. Although the prevalence of RET/PTC rearrangements is generally found to be low in adults 
and high in children, and children are more susceptible to the effects of radiation, conflicting data do exist. For instance, a study by Elisei et al. (2001) on different groups of thyroid tumor patients with various ethnic and demographic backgrounds showed no association of the occurrence of RET/PTC with age at the time of radiation exposure, albeit with relatively low numbers of study subjects in the cancer groups. This study also showed no difference in the occurrence of $R E T / P T C$ in radiation-exposed and non-exposed adult patients.

Therefore, studies in general demonstrate a reciprocal age-association of $B R A F$ mutation and RET/PTC in PTC. Beyond inciting factors, such as radiation, age is apparently an important factor in determining the dominance of the two genetic alterations in PTC. $B R A F$ mutation tends to occur in adults and is a major somatic genetic alteration that drives the formation of PTC in this population, whereas RET/PTC tends to occur in children and is a major somatic genetic alteration that drives the formation of PTC in this population. It appears that young age itself, in addition to radiation, is an important predisposing factor for the development of $R E T / P T C$ and subsequent PTC. The concept that $R E T / P T C$ is an initiator of the formation of PTC in nuclear-accident victims is somewhat challenged by a recent study of Unger et al. (2004) on Chernobyl-associated PTC. In this study, using an interphase in situ hybridization technique, the authors found $R E T / P T C$ rearrangements in some cells of PTC tumors but not in other cells of the same tumor. This raises the possibility that these PTCs might have arisen from different clones or that $R E T / P T C$ is a late subclonal event, and thereby challenges the general belief that $R E T / P T C$ plays an initiating role in the development of radiationassociated PTC. However, the possibility of inaccurate scoring of, and therefore missing, tumor cells harboring RET/PTC rearrangement due to a technical limitation in this study has been raised (Fagin 2004). Ionizing radiation could induce the formation of $R E T / P T C$ in both transplanted human thyroid tissues in mice (Mizuno et al. 1997) and in cultured thyroid tumor cells (Ito et al. 1993). A high prevalence of $R E T / P T C$ was also observed in PTC that developed in patients who had external radiation treatment during childhood (Bounacer et al. 1997). The transgenic mouse model demonstrated clearly the ability of RET/PTC1, 2 and 3 to initiate the development of PTC (Jhiang et al. 1996, 1998, Santoro et al. 1996, Powell et al. 1998). Therefore, radiation must have played an important role in the development of $R E T / P T C$ and PTC in Chernobyl nuclear accident victims. However, it has long been known that childhood radiation exposure is associated with a higher incidence of thyroid cancer (Duffy \& Fitzgerald 1950, Wood et al. 1969, Shore et al. 1985). Radioiodine exposure in fallouts from a thermonuclear test (Conard et al. 1970) and the Chernobyl accident (Kazakov et al. 1992) was followed by a significantly increased incidence of thyroid cancer and, as studied and revealed in the latter case, $R E T / P T C$ primarily in child victims. The finding that young age is a risk factor for the development of $R E T / P T C$-positive PTC even in non-radiation-exposed children additionally supports the possibility that young age itself predisposes to $R E T / P T C$ development through an unidentified mechanism. It is possible that young age may predispose $R E T / P T C$-harboring PTC to more rapid growth and progression so PTC harboring this genetic alteration may tend to be caught clinically early in life. It would be consistent with this idea to confirm, in a large series of tumors, that the tumor size of $R E T / P T C$-positive PTC in the pediatric population is larger than that of $R E T / P T C$-positive PTC in the adult population.

In contrast to the association of young age with $R E T / P T C$, the studies on BRAF mutation in adult and pediatric populations summarized above clearly show that old age is a predisposing factor for the development of BRAF mutation and PTC harboring this mutation. The prevalence of $B R A F$ mutation in PTC was similarly high in radiation-exposed and nonexposed adult patients (Xing et al. 2004b). In an adult population, Nikiforova et al. (2003) further showed a significant association of $B R A F$ mutation with older age. The study on adult patients by $\mathrm{Xu}$ et al. (2003) also showed a clear tendency of association of $B R A F$ mutation with older age, although no statistical significance was reached. Other studies on adult patients did not reveal a specific age predilection of $B R A F$ mutation. In most of these studies, however, the number of study subjects was small or the age range of the study subjects was not sufficiently wide and evenly distributed to reveal a clear association between age and the BRAF mutation. The fundamental basis for this link between older age and the development of $B R A F$ mutation remains unclear. It also remains uncertain whether $B R A F$ mutation-harboring PTC is more slowly growing than $R E T / P T C$-harboring PTC so that the former tends to be caught clinically later in life. If proven to be the case, this could at least partially explain the reciprocal age distribution of $B R A F$ mutation and $R E T / P T C$ rearrangements, at least in the non-radiation-exposed population. Regardless of the underlying mechanism, there appears to be an age window below which $R E T / P T C$ tends to occur or to be identified and above which $B R A F$ mutation tends to 
Table 4 BRAF mutation in thyroid fine-Needle aspiration biopsy (FNAB) specimens

\begin{tabular}{|c|c|c|c|c|c|c|c|}
\hline \multirow[b]{3}{*}{ Report } & \multicolumn{6}{|c|}{ Frequency (mutation/total (\%)) } & \multirow[b]{3}{*}{ Reference } \\
\hline & \multicolumn{3}{|c|}{ Histological diagnosis of the nodule } & \multicolumn{3}{|c|}{ Cytologically indeterminate } & \\
\hline & PTC & FTC & Benign & Cancer & Benign & Total & \\
\hline 1 & $22 / 54(41)$ & $0 / 2(0)$ & $0 / 32(0)$ & $5 / 32(16)$ & $0 / 23(0)$ & $5 / 55(9)$ & Cohen et al. 2004 \\
\hline 2 & $26 / 69(38)$ & - & $0 / 27(0)$ & $4 / 15(27)$ & $0 / 19$ & $4 / 34(12)$ & Salvatore et al. 2004 \\
\hline 3 & $8 / 16(50)$ & $0 / 6(0)$ & $0 / 21(0)$ & $2 / 14(14)$ & $0 / 12(0)$ & $2 / 26(8)$ & Xing et al. $2004 c$ \\
\hline 4 & - & - & - & - & - & $2 / 45(4)$ & Baloch et al. $2004^{*}$ \\
\hline 5 & $30 / 58(51)$ & - & - & $1 / 8(13)$ & - & $1 / 8(13)$ & Hayashida et al. 2004 \\
\hline Overall & 86/197 (44) & $0 / 8(0)$ & $0 / 80$ & $12 / 69$ (17) & $0 / 54(0)$ & $14 / 168(8)$ & \\
\hline
\end{tabular}

*This report is an abstract without complete information at this time, and their data cannot be included fully for discussion in this review.

occur or to be identified. The data currently available suggest that in most patients, this age window is likely to occur around the late teenage years, but the definition of the precise age range will need a large series of patients with a wide and evenly distributed age range. Knowing this age window may help predict the type of genetic alteration that a patient's thyroid cancer may harbor.

\section{The diagnostic value of $B R A F$ mutation in thyroid cancer}

Thyroid nodules are common, and are palpable in approximately $5 \%$ of normal adults (Vander et al. 1968) and visualized by sonography in one-third or more of normal adults (Brander et al. 1991, Bruneton et al. 1994). As about $5-8 \%$ of palpable thyroid nodules are cancerous, a major task of the initial evaluation of thyroid nodules is to rule out malignancy (Werk et al. 1984, Belfiore et al. 1989). Thyroid fineneedle aspiration biopsy (FNAB) with cytological analysis is a widely used initial diagnostic measure in thyroid nodule evaluation (Hegedus 2004). However, at least $20 \%$ of biopsies yield indeterminate cytological findings that cannot distinguish between thyroid cancer and benign tumors with certainty, leaving uncertain the optimal management for these patients (Gharib et al. 1984, Sclabas et al. 2003). As the T1799A $B R A F$ mutation occurs exclusively in PTC with a high prevalence, but not in benign thyroid neoplasms (Table 1), it is a specific diagnostic marker for thyroid cancer. Several studies have been conducted to evaluate the diagnostic applicability of $B R A F$ mutation detection on FNAB specimens (Baloch et al. 2004, Cohen et al. 2004, Hayashida et al. 2004, Salvatore et al. 2004, Xing et al. 2004c). Most of these studies were retrospective, in which $B R A F$ mutation was analyzed on FNAB specimens retrieved from existing cytological slides and in which the BRAF mutation status was correlated with the pre-established histopathological diagnoses of the tumors. The study by Xing et al. (2004c) was a prospective one, in which FNAB was performed, $B R A F$ mutation analyzed preoperatively, and the results then correlated prospectively with the postoperative histological diagnosis of the biopsied thyroid nodule. Regardless of the detection methods used, all these studies demonstrated excellent accuracy and simplicity of $B R A F$ mutation detection on FNAB specimens. For $B R A F$ mutation-positive PTC, the diagnostic specificity and sensitivity of $B R A F$ mutation detection on FNAB specimens were $100 \%$ in these studies. Consistent with the studies on primary tumors, in FNAB specimens, BRAF mutation was found only in histologically-proven PTC, but not in FTC and benign thyroid tumors (Table 4). The overall prevalence of $B R A F$ mutation in PTC in these FNAB studies was $44 \%$, similar to the generally reported prevalence of this mutation (Table 1). It is therefore expected that, as demonstrated by these FNAB studies (Table 4), nearly half of patients with PTC can be diagnosed solely based on $B R A F$ mutation analysis on FNAB specimens. If the diagnostic reliability of this $B R A F$ mutation approach is confirmed in more studies, PTC diagnosed solely based on BRAF mutation detection will probably not need further diagnostic cytology studies. BRAF mutation detection is robust and low in cost (Xing et al. 2004c), particularly if it can be done in a centrally coordinated laboratory with appropriate methods. In view of the high prevalence of both $B R A F$ mutation and PTC, the elimination of the need for cytology examination in nearly half of the patients with PTC undergoing FNAB evaluation could be substantially cost-saving. Moreover, BRAF mutation detection may allow for more specific diagnosis of PTC as inter-observer variations in interpreting the cytology patterns of 
FNAB specimens do exist (Greaves et al. 2000, AlShaikh et al. 2001). In fact, this point is well illustrated by the study of Baloch et al. (2004), in which $13 \%$ (seven of 53) of FNAB specimens cytologically read as benign and 7\% (one of 14) of FNAB specimens read as thyroiditis were positive for $B R A F$ mutation and the diagnoses were able to be corrected to PTC by mutation analysis.

Nevertheless, BRAF mutation detection alone on FNAB specimens is unlikely to solve the diagnostic dilemma of indeterminate cytology on FNAB. As summarized in Table $4,17 \%$ of thyroid cancers with indeterminate cytology can be diagnosed by $B R A F$ mutation analysis. When all the cases with indeterminate cytology were evaluated as a whole, only a small portion $(8 \%)$ of the patients could be diagnosed with $B R A F$ mutation detection. This is because the majority of thyroid tumors with indeterminate cytology are benign thyroid neoplasms harboring no $B R A F$ mutation and only about $15 \%$ of thyroid tumors with indeterminate cytology prove to be PTC (Sclabas et al. 2003). Given the overall prevalence of $B R A F$ mutation of around $45 \%$ in PTC (Table 1), $15 \%$ as PTC of the cytologically indeterminate cases can be translated into about $7 \%$ that will be positive for $B R A F$ mutation, consistent with the BRAF mutation rate found on indeterminate cytological specimens in the several recent reports (Table 4). Moreover, many of the thyroid cancers with indeterminate cytology, particularly those with follicular neoplasm patterns, are FTC and follicular-variant PTC, with the former harboring no $B R A F$ mutation and the latter carrying the mutation at a very low prevalence (Tables 1 and 2). Obviously, a positive $B R A F$ mutation has a perfect positive predictive value and can establish the diagnosis of PTC, but a negative result in a specific patient will not be of any diagnostic value. It remains to be demonstrated definitively how effective $B R A F$ mutation analysis on thyroid FNAB can truly be in addressing the diagnostic dilemma of indeterminate cytology. Nearly 300000 new thyroid nodules are detected annually in the United States (Castro \& Gharib 2000). If all of these thyroid nodules are to be evaluated with FNAB, approximately 90000 (assuming a $30 \%$ rate of indeterminate cytology) of them may yield indeterminate cytological findings. With a diagnostic sensitivity of $8 \%$ (Table 4 ) for $B R A F$ mutation detection on cytologically indeterminate FNAB, about 7200 patients per year in the United States could be helped with a definitive diagnosis of PTC by this technique and the optimal management of these patients could be pursued. Practically, it may be worth testing $B R A F$ mutation on readily retrievable FNAB specimens from cytology slides when conservative follow-up of a cytologically indeterminate thyroid nodule is clinically debatable in a patient. The combination of $B R A F$ mutation with additional sensitive and specific molecular markers will likely be the next step in increasing the FNAB diagnostic sensitivity. This approach was tested recently by combined use of $B R A F$ mutation with $R E T / P T C$ (Salvatore et al. 2004), a process which did indeed improve the diagnostic sensitivity. However, the diagnostic specificity of this approach needs to be further investigated on large studies as $R E T / P T C$ is sometimes found in benign thyroid tumors (Nikiforov 2002, Santoro et al. 2002, Tallini 2002). Combined use of $B R A F$ mutation with Ras mutation in conjunction with FNAB to diagnose thyroid cancer is also being investigated (Baloch et al. 2004), but a similar diagnostic specificity limitation also potentially exists as Ras mutations are also frequently seen in benign thyroid neoplasms (Tallini 2002, Vasko et al. 2003).

As cancer cells can dislodge into the bloodstream, efforts have been made to establish sensitive methods to detect $B R A F$ mutation that could potentially be used on serum DNA samples. The technique of singlestranded DNA conformation polymorphism was recently used to detect $B R A F$ mutation in plasma DNA from thyroid cancer patients, but apparently failed to provide sufficient sensitivity (Vdovichenko et al. 2004). Real-time allele-specific amplification for detection of the BRAF mutation was tested, which allowed detection of $1 \%$ mutated allele in a DNA sample (Jarry et al. 2004), a sensitivity that is unlikely to be sufficient for detection of mutated $B R A F$ allele in blood samples. Lilleberg et al. (2004) recently reported the use of mutant allele-specific PCR amplification followed by detection with a denaturing HPLC platform that uses post-separation fluorescence technology to detect mutated alleles that represent $<0.1 \%$ of the total analyzed DNA. With this method, the authors were able to scan for $B R A F$ mutation as well as various ras mutations in plasma DNA from patients with colon cancer with $100 \%$ sensitivity. It remains to be tested whether this method can also be applied to thyroid cancer patients. The gap ligase chain-reaction technique was demonstrated to be a more sensitive method and could detect point mutations in the presence of up to 10000 -fold excess of wild-type allele DNA (Abravaya et al. 1995). A modified version of this method specifically for $B R A F$ point mutation was developed recently and, with its high sensitivity, was used to rule out $B R A F$ mutation in primary biliary tract cancers (Goldenberg et al. 2004). It would be interesting to see whether this stable and sensitive 
method could reliably detect $B R A F$ mutation in the serum DNA of thyroid cancer patients or other $B R A F$ mutation-positive cancer patients. Using an even more sensitive sequence-specific real-time PCR technique, Rosenberg et al. (2004) were able to detect one heterozygous $B R A F$ mutation-positive cell mixed in 21692 normal cells. When applying it to blood samples, the authors were able to identify circulating $B R A F$ mutation in one of five PTC patients tested. This encouraging method needs to be validated in a larger study. It is hoped that a sensitive and specific method to detect $B R A F$ mutation in the blood, which could simplify the diagnostic evaluation of a large number of patients undergoing thyroid nodule evaluation, will be established in the near future; a positive $B R A F$ mutation test on the blood may spare the patient from FNAB and other diagnostic procedures and prompt direct surgical treatment.

\section{Prognostic value of BRAF mutation in thyroid cancer}

Because $B R A F$ mutation plays an important role in PTC tumorigenesis, it is conceivable that this mutation is a determinant of clinical and pathological behaviors of PTC and could be a novel prognostic factor for this cancer. The relationship between this mutation and the clinicopathological outcomes of PTC have been investigated in several studies (Namba et al. 2003, Nikiforova et al. 2003, Xu et al. 2003, Fugazzola et al. 2004, Kim et al. 2004, Puxeddu et al. 2004; M. Xing et al. unpublished results). In a series of 104 PTCs, comprised mainly of American patients, Nikiforova et al. (2003) reported a significant association of $B R A F$ mutation with extrathyroidal invasion $[(16 / 38(42 \%)$ with $B R A F$ mutation versus $13 / 66(20 \%)$ without mutation, $P=0.03)$ ] and advanced stages [(for stage III, $10 / 38(26 \%)$ with $B R A F$ mutation versus $2 / 66(3 \%)$ without mutation, $P=0.006$; for stage IV, $7 / 38(18 \%)$ with $B R A F$ mutation versus $3 / 66 \quad(4 \%)$ without mutation, $P=0.03)$ ] of the primary tumor at the time of initial surgery. In a Japanese series of 126 PTCs, Namba et al. (2003) found a significant association of $B R A F$ mutation with advanced stages of the tumor and distant metastasis $[(7 / 38 \quad(18 \%)$ with $B R A F$ mutation versus $5 / 88 \quad(6 \%)$ without mutation, $P=0.033)]$. In a recent Korean study, BRAF mutation was found to be significantly associated with neck lymph node metastasis $[(39 / 58 \quad(67 \%)$ with $B R A F$ mutation versus $4 / 12 \quad(33 \%)$ without mutation, $P=0.048]$ (Kim et al. 2004). In two Italian studies (Fugazzola et al. 2004, Puxeddu et al. 2004) and an
American study by $\mathrm{Xu}$ et al. (2003), no significant association of $B R A F$ mutation with any of the common high-risk pathological characteristics was revealed. The number of the cases examined in these latter three studies was much smaller, however, ranging from 56 to 60 . In some of the studies (Nikiforova et al. 2003, Xu et al. 2003, Fugazzola et al. 2004), a trend in association between BRAF mutation and lymph node metastasis was observed but did not achieve statistical significance. In the study by Fugazzola et al. (2004), a higher but non-significant recurrence rate of thyroid cancer was found to be associated with $B R A F$ mutation. Our recent study on a large series of PTCs demonstrated a significant association of $B R A F$ mutation with extrathyroidal invasion, lymph node metastasis, advanced tumor stages, and cancer recurrence, which still existed on multivariate analysis even with adjustment for all the common confounding clinicopathological factors (M Xing et al. unpublished results). In this study, we found a thyroid cancer recurrence rate of $25 \%$ in $B R A F$ mutation-positive patients versus $9 \%$ in $B R A F$ mutation-negative patients $(P=0.004)$. Interestingly, we also observed a significantly higher incidence of the loss of radioiodine avidity in the recurrent thyroid cancer when $B R A F$ mutation was positive, suggesting that $B R A F$ mutation may not only predict a higher incidence of thyroid cancer recurrence but also predict a poorer response of recurrent thyroid cancers to radioiodine treatment. Only one study (Xu et al. 2003) showed an association of BRAF mutation with (male) gender. None of the studies showed association of $B R A F$ mutation with larger tumor size, suggesting that $B R A F$ mutation increases the aggressiveness of PTC by promoting its invasiveness, metastasis, and recurrence, but not growth in size of the primary tumor.

Most of the studies on the relationship between $B R A F$ mutation and the clinicopathological outcomes of PTC were conducted without subtype stratification of PTC. As discussed above, BRAF mutation occurs mostly in conventional and tall-cell PTC and uncommonly in follicular-variant PTC. Compared with conventional PTC, follicular-variant PTC is infrequently associated with high-risk pathological characteristics such as lymph node metastasis and extrathyroidal invasion. Therefore, the inconsistent results from different reports on the association of $B R A F$ mutation with high-risk pathological characteristics could be partially due to different combinations of various subtypes of PTC that were included in the study. For example, a significant association of $B R A F$ mutation with high-risk pathological factors could be shown on a series of PTC that is comprised of certain proportions 
of follicular-variant PTC and conventional PTC, while this association may be lost on analysis within a specific subtype of PTC, particularly when the sample number is small. This illustrates the importance of the use of multivariate analysis with adjustment for various confounding factors, including histological subtypes of PTC, as we did recently to establish an independent prognostic role of $B R A F$ mutation (M Xing et al. unpublished results). As the $B R A F$ mutation is so prevalent in conventional or tall-cell PTC, a large series of such cases may be needed to reveal an association of $B R A F$ mutation with poorer clinicopathological outcomes within these subtypes of PTC. A recent Korean study by Kim et al. (2004) focused specifically on conventional PTC and showed a significant association of $B R A F$ mutation with lymph node metastasis. Overall, the data available to date support the idea that $B R A F$ mutation is an independent prognostic factor that predicts a poorer prognosis of PTC. As mentioned above, the demonstration of BRAF mutant-induced development of PTC and its transition into ATC in transgenic mice (Knauff et al. $2004)$ is consistent with the clinical findings on the role of $B R A F$ mutation in predicting a poor outcome of PTC.

Whether to treat a PTC patient with radioiodine, and how vigilantly and aggressively to guard against recurrence, are often questions without straightforward clinical answers. Use of $B R A F$ mutation status may help clarify such clinical situations and assist clinical decision making. It is expected that $B R A F$ mutation may also be useful in risk and prognostic evaluation of micro PTC. Although this type of thyroid cancer is generally thought to be indolent and associated with a relatively good prognosis, local and distant metastasis and recurrence do occur, and no specific independent prognostic clinicopathological factors were identified on multivariate analysis for this type of PTC (Chow et al. 2003). As BRAF mutation often occurs in micro PTC as well (Nikiforova et al. 2003, Sedliarou et al. 2004, Trovisco et al. 2004), it would be interesting to investigate $B R A F$ mutation as an independent prognostic factor to help manage these patients more appropriately.

As $B R A F$ mutation can be readily analyzed on FNAB specimens (Baloch et al. 2004, Cohen et al. 2004, Salvatore et al. 2004, Xing et al. 2004c), preoperative $B R A F$ mutation analysis, in conjunction with routine FNAB cytology study, could help surgeons better tailor their surgical procedures by helping them choose, for instance, between vigilant exploration and resection of suspicious regional lymph node and no neck dissection, and between total thyroidectomy and lobectomy. The current standard prognostic evaluation of thyroid cancer is based largely on clinicopathological criteria, which is often incomplete, particularly preoperatively, when the pathological characteristics of the tumor are not known. $B R A F$ mutation represents the first molecular marker that can be used, even preoperatively, for more efficient prognostic evaluation and clinical management of PTC. Therefore, it may be reasonable to examine $B R A F$ mutation on preoperative FNAB specimens for every patient not only for diagnostic purposes, but also for risk evaluation. In this sense, $B R A F$ mutation may be examined on FNAB specimens even if a diagnosis of PTC is already known based on cytological studies. This approach may assist clinicians in optimizing both the short-term (surgical) and long-term (medical) management of their thyroid cancer patients.

\section{Therapeutic potential of inhibiting the MAP kinase pathway using novel inhibitors in thyroid cancer}

Although thyroid cancer is usually indolent and curable with the current standard treatments of surgery, often followed by adjuvant radioiodine therapy, there remain many patients whose conditions are incurable, disabling, and even fatal. The most difficult cases, for which there is no effective current treatment, are those that are inoperable and have lost radioiodine avidity. This includes ATC, which is often positive for BRAF mutation (Table 1). A novel effective treatment is needed desperately for these patients (Sherman 2003). As activation of the MAP kinase pathway by various genetic alterations, including $B R A F$ mutation, plays a pivotal role in thyroid tumor genesis and progression, efforts targeted at inhibiting this pathway may lead to development of novel effective therapy for thyroid cancer.

A therapeutic approach targeted at the Raf kinases has been tested for human cancers using specific inhibitors with encouraging results in in vitro cell studies and in vivo animal studies (Wilhelm \& Chien 2002, Bollag et al. 2003, Dumas et al. 2004). Among these inhibitors, the Bay 43-9006 compound seems to be a promising one as it has excellent safety profile in human subjects and effectiveness in inhibiting Raf kinases (Bollag et al. 2003, Lee \& McCubrey 2003). The Bay 43-9006 compound is in several clinical trials at various phases targeted at several types of human cancer (Lee \& McCubrey 2003). Although this compound most potently inhibits the C-type Raf kinase, it also has excellent potency in inhibiting 
wild-type and V600E mutant BRAF kinases (Karasarides et al. 2004, Wan et al. 2004). X-ray crystallography has recently demonstrated the binding of this inhibitor with the kinase domain in both the wild-type and V600E BRAF kinases (Garnett \& Marais 2004, Wan et al. 2004). By binding with the kinase domain of BRAF, Bay 43-9006 locks the kinase in an inactive state. Treatment with this compound can block kinase signaling downstream of Raf kinase, inhibit BRAFstimulated DNA synthesis and cell proliferation, induce apoptosis in melanoma cells harboring $B R A F$ mutation, and delay the growth of melanoma tumor xenografts in mice (Karasarides et al. 2004). A recent preliminary study by Kumar et al. (2004) has shown that Bay 43-9006 can inhibit the growth and proliferation, and induce apoptosis, of KAT-5 cells, a PTC-derived cell line harboring the $B R A F$ mutation. As BRAF is the predominant type of Raf kinase in follicular thyroid cells (Fagin 2004) and as BRAF mutation is highly prevalent in PTC (Table 1), strategies targeted at inhibition of BRAF may be particularly effective for the treatment of PTC. Several other MAP kinase pathway inhibitors acting at steps other than Raf kinases have also been developed, including MEK inhibitors (Sebolt-Leopold 2004). A good example is the MEK-specific inhibitor CI-1040, which is the first MEK-targeted drug candidate to undergo clinical trials, although monotherapy with this drug in some cancers did not clearly prove to be effective on a multicenter phase II study (Rinehart et al. 2004). It remains to be investigated whether these MAP kinase pathway inhibitors may have therapeutic effects in thyroid cancer patients.

Several earlier studies demonstrated that the transformation of thyroid cells with ras oncogene induced loss of expression of thyroid-specific proteins such as thyroid-stimulating hormone (TSH) receptor (TSHR) (Berlingieri et al. 1990) and thyroglobulin (Avvedimento et al. 1991). A recent study by Knauf et al. (2003) demonstrated that acute expression of RET/PTC3, H-Ras, or constitutively activated MEK-1 could all block TSH-induced expression of thyroglobulin and sodium-iodide symporter (NIS) in PCCL3 thyroid cells. This study also demonstrated that treatment of cells with MEK inhibitors could restore the expression of thyroglobulin and NIS. Interestingly, the transgenic mice in which development of PTC and its transition to ATC were induced by V600E $B R A F$ mutation had absent or decreased expression of thyroglobulin and developed hypothyroidism (Knauf et al. 2004). Normal expression of these thyroid-specific molecules is essential for the unique function of thyroid cells to take up and metabolize iodide and synthesize thyroid hormones (Nilsson 2001). It therefore appears that silencing of thyroidspecific genes by aberrant activation of the MAP kinase pathway may be the basis for the loss of radioiodine avidity seen clinically in some thyroid cancer patients. Aberrant methylation was shown to be a mechanism for silencing some of the thyroid-specific genes involved in iodide metabolism, including those for NIS (Venkataraman et al. 1999), TSHR (Xing et al. 2003a), and pendirn (Xing et al. 2003b) in thyroid cancer. It is thus plausible to propose that inhibiting the MAK kinase pathway could reverse the aberrant methylation of these genes and restore their expression and the lost iodide-concentrating ability of thyroid cancer cells. In this sense, the MAP kinase pathway inhibitors could be particularly useful as a conjunction therapy with radioiodine treatment of those patients whose thyroid cancers have decreased or lost radioiodine avidity. These hypotheses need to be tested.

The MAP kinase pathway-activating $B R A F$ mutation, ras mutations, RET/PTC, and RASSFIA methylation may together account for nearly all follicular epithelial cell-derived thyroid cancers (Xing et al. 2004a), and these common genetic alterations may all induce thyroid tumor genesis and progression through the MAP kinase pathway, either entirely or partially. Therefore, the MAP kinase pathway inhibitors may be effective in treating a wide range of thyroid cancers, irrespective of $B R A F$ mutation status. With the proven safety profiles of the Raf kinase inhibitor Bay 43-9006 and the MEK inhibitor CI-1040 in clinical trials on other cancers, a well-designed phase II clinical trial on these novel MAP kinase pathway inhibitors is now needed for thyroid cancer patients, particularly for those with incurable disease. Before such a clinical trial is conducted, more preclinical studies on the anticancer effects of these compounds in thyroid cancer cell lines and tumor xenograft animal models will provide important implications and necessary support for such clinical trials.

\section{Summary and future directions}

The discovery of the $B R A F$ mutation in thyroid cancer represents one of the most important recent advancements in thyroid cancer research and is of significant clinical potential in thyroid cancer medicine. Since the initial report on $B R A F$ mutation in thyroid cancer nearly 2 years ago, rapid progress has occurred due to an explosion of research in this area. The T1799A $B R A F$ mutation is the most common activating genetic alteration in thyroid cancer. Advancements have also been made in understanding the relationship between 
$B R A F$ mutation and other common genetic alterations in thyroid cancer, and of particular note is the discovery of BRAF mutation's mutual exclusivity with other well-established genetic alterations, a finding which points toward an independent role of $B R A F$ mutation in thyroid tumorigenesis. The results from transgenic mouse studies have unequivocally established the role of $B R A F$ mutation in the initiation and progression of PTC. The reciprocal age association between $B R A F$ mutation and $R E T / P T C$ rearrangements is interesting, although it remains without a clear explanation at this time. More recent studies have been focused on the clinical significance of the $B R A F$ mutation, particularly its diagnostic and prognostic values. As the T1799A BRAF mutation does not occur in benign thyroid tumors, it is a specific diagnostic marker for thyroid cancer when used in conjunction with FNAB, albeit with a low sensitivity for cases with indeterminate cytology. The association of $B R A F$ mutation with poor clinicopathological outcomes, demonstrated by several relatively large studies, has established that this mutation is a novel prognostic molecular marker and may add a new dimension to the conventional risk evaluation of thyroid cancer. Preoperative knowledge of the $B R A F$ mutation status of the thyroid tumor, through mutation analysis on FNAB cytological specimens, may be particularly valuable as it can assist clinicians in more efficiently planning and optimizing both the short- and long-term managements of thyroid cancer patients. Studies aimed at the therapeutic potential of novel inhibitors of the MAP kinase pathway for the treatment of thyroid cancer may yield important breakthroughs.

Further work is needed in the following several areas: (1) the elucidation of the specific molecular and cellular alterations and events that are caused by $B R A F$ mutation and MAP kinase pathway activation in thyroid cancer; (2) the possible restoration of the ability of thyroid cancer cells to metabolize iodide by interfering with $B R A F$ mutation-initiated aberrant signaling; (3) the improvement of the diagnostic utility of $B R A F$ mutation, possibly through combination with other specific molecular markers for thyroid cancer in conjunction with FNAB, and through the establishment of a $B R A F$ mutation-based blood test; (4) the clinical application of the prognostic value of $B R A F$ mutation in guiding the optimal short- and long-term managements of thyroid cancer patients and (5) further preclinical and clinical studies on the therapeutic potential of novel inhibitors of MAP kinase pathway. It is anticipated that rapid advancements in these areas will occur in the next few years.

\section{Acknowledgements}

I wish to thank Dr P W Ladenson and Dr D Sidransky for their critical comments and inputs. I also wish to thank Dr W H Westra, Dr R P Tufano, Dr E Rosenbaum, Dr Y Cohen, Dr K J Rhoden, Ms K A Carson, Dr V Vasko, Dr A Larin, Dr G Tallini, Dr S Tolaney, Dr E H Holt, Dr P Hui, Dr C B Umbricht, Dr S Basaria, Ms M Ewertz, Dr A P Tufaro, Dr J A Califano, Dr M D Ringel, Dr M A Zeiger, Dr G Wu, Dr B Trink, and other colleagues for their generous support and collaboration. I admire the investigators cited in this review for their outstanding work. I intended to cite all the published work in this area, but apologize for the possible, unintended, omission of any relevant references.

\section{Funding}

This work is supported by a research grant from the Flight Attendant Medical Research Institute and a Johns Hopkins Clinician Scientist Award, which partially support the research work in my laboratory. The authors declare that there is no conflict of interest that would prejudice the impartiality of this scientific work.

\section{References}

Abravaya K, Carrino JJ, Muldoon S \& Lee HH 1995 Detection of point mutations with a modified ligase chain reaction (Gap-LCR). Nucleic Acids Research 23 675-682.

Akslen LA \& LiVolsi VA 2000 Prognostic significance of histologic grading compared with subclassification of papillary thyroid carcinoma. Cancer 88 1902-1908.

Al-Shaikh A, Ngan B, Daneman A \& Daneman D 2001 Fineneedle aspiration biopsy in the management of thyroid nodules in children and adolescents. Journal of Pediatrics 138 140-142.

Avvedimento VE, Musti AM, Ueffing M, Obici S, Gallo A, Sanchez M, DeBrasi D \& Gottesman ME 1991 Reversible inhibition of a thyroid-specific trans-acting factor by Ras. Genes and Development 5 22-28.

Baloch Z, Kumar MS, Lai M, Volpe P, LiVolsi VA, Mandel SJ \& Brose MS 2004 Rate of BRAF and $N$-Ras mutations in thyroid nodules undergoing fine needle aspiration. Thyroid 14745.

Basolo F, Giannini R, Monaco C, Melillo RM, Carlomagno F, Pancrazi M, Salvatore G, Chiappetta G, Pacini F, Elisei R et al. 2002 Potent mitogenicity of the RET/PTC3 oncogene correlates with its prevalence in tall-cell variant of papillary thyroid carcinoma. American Journal of Pathology 160 247-254.

Begum S, Rosenbaum E, Henrique R, Cohen Y, Sidransky D \& Westra WH 2004 BRAF mutations in anaplastic thyroid 
carcinoma: implications for tumor origin, diagnosis and treatment. Modern Pathology 17 1359-1363.

Belfiore A, Giuffrida D, La Rosa GL, Ippolito O, Russo G, Fiumara A, Vigneri R \& Filetti S 1989 High frequency of cancer in cold thyroid nodules occurring at young age. Acta Endocrinologica (Copenhagen) 121 197-202.

Berlingieri MT, Akamizu T, Fusco A, Grieco M, Colletta G, Cirafici AM, Ikuyama S, Kohn LD \& Vecchio G 1990 Thyrotropin receptor gene expression in oncogenetransfected rat thyroid cells: correlation between transformation, loss of thyrotropin-dependent growth, and loss of thyrotropin receptor gene expression. Biochemical and Biophysical Research Communications 173 172-178.

Bollag G, Freeman S, Lyons JF \& Post LE 2003 Raf pathway inhibitors in oncology. Current Opinion in Investigative Drugs 4 1436-1441.

Bongarzone I \& Pierotti MA 2003 The molecular basis of thyroid epithelial tumorigenesis. Tumori 89 514-516.

Bounacer A, Wicker R, Caillou B, Cailleux AF, Sarasin A, Schlumberger M \& Suarez HG 1997 High prevalence of activating ret proto-oncogene rearrangements, in thyroid tumors from patients who had received external radiation. Oncogene 15 1263-1273.

Brander A, Viikinkoski P, Nickels J \& Kivisaari L 1991 Thyroid gland: US screening in a random adult population. Radiology $181683-687$.

Bruneton JN, Balu-Maestro C, Marcy PY, Melia P \& Mourou MY 1994 Very high frequency (13 MHz) ultrasonographic examination of the normal neck: detection of normal lymph nodes and thyroid nodules. Journal of Ultrasound in Medicine 13 87-90.

Bunone G, Uggeri M, Mondellini P, Pierotti MA \& Bongarzone I 2000 RET receptor expression in thyroid follicular epithelial cell-derived tumors. Cancer Research 60 2845-2849.

Castro MR \& Gharib H 2000 Thyroid nodules and cancer. When to wait and watch, when to refer. Postgraduate Medicine 107 113-116, 119-120, 123-124.

Chan JK 1990 Papillary carcinoma of thyroid: classical and variants. Histology and Histopathology 5 241-257.

Cheng G \& Meinkoth JL 2001 Enhanced sensitivity to apoptosis in Ras-transformed thyroid cells. Oncogene $\mathbf{2 0}$ 7334-7341.

Cheung L, Messina M, Gill A, Clarkson A, Learoyd D, Delbridge L, Wentworth J, Philips J, Clifton-Bligh R \& Robinson BG 2003 Detection of the PAX8-PPAR gamma fusion oncogene in both follicular thyroid carcinomas and adenomas. Journal of Clinical Endocrinology and Metabolism 88 354-357.

Chow SM, Law SC, Chan JK, Au SK, Yau S \& Lau WH 2003 Papillary microcarcinoma of the thyroid-Prognostic significance of lymph node metastasis and multifocality. Cancer 98 31-40.

Ciampi R, Knauf JA, Kerler R, Gandhi M, Zhu Z, Nikiforova MN, Rabes HM, Fagin JA \& Nikiforov YE 2005 Oncogenic AKAP9-BRAF fusion is a novel mechanism of MAPK pathway activation in thyroid cancer. Journal of Clinical Investigation 115 94-101.

Cohen Y, Xing M, Mambo E, Guo Z, Wu G, Trink B, Beller U, Westra WH, Ladenson PW \& Sidransky D 2003 BRAF mutation in papillary thyroid carcinoma. Journal of National Cancer Institute 95 625-627.

Cohen Y, Rosenbaum E, Clark DP, Zeiger MA, Umbricht CB, Tufano RP, Sidransky D \& Westra WH 2004 Mutational analysis of $B R A F$ in fine needle aspiration biopsies of the thyroid: a potential application for the preoperative assessment of thyroid nodules. Clinical Cancer Research 10 2761-2765.

Conard RA, Dobyns BM \& Sutow WW 1970 Thyroid neoplasia as late effect of exposure to radioactive iodine in fallout. Journal of the American Medical Association 214 316-324.

Dammann R, Li C, Yoon JH, Chin PL, Bates S \& Pfeifer GP 2000 Epigenetic inactivation of a RAS association domain family protein from the lung tumor suppressor locus 3p21.3. Nature Genetics 25 315-319.

Davies H, Bignell GR, Cox C, Stephens P, Edkins S, Clegg S, Teague J, Woffendin H, Garnett MJ, Bottomley W et al. 2002 Mutations of the $B R A F$ gene in human cancer. Nature 417 949-954.

Dhillon AS \& Kolch W 2004 Oncogenic B-Raf mutations: crystal clear at last. Cancer Cell 5 303-304.

Duffy BJ Jr \& Fitzgerald PJ 1950 Cancer of the thyroid in children: a report of 28 cases. Journal of Clinical Endocrinology and Metabolism 10 1296-1308.

Dumas J, Smith RA \& Lowinger TB 2004 Recent developments in the discovery of protein kinase inhibitors from the urea class. Current Opinion in Drug Discovery and Development 7 600-616.

Elisei R, Romei C, Vorontsova T, Cosci B, Veremeychik V, Kuchinskaya E, Basolo F, Demidchik EP, Miccoli P, Pinchera A et al. $2001 \mathrm{RET} / \mathrm{PTC}$ rearrangements in thyroid nodules: studies in irradiated and not irradiated, malignant and benign thyroid lesions in children and adults. Journal of Clinical Endocrinology and Metabolism 86 3211-3216.

Fagin JA 2002 Minireview: branded from the start-distinct oncogenic initiating events may determine tumor fate in the thyroid. Molecular Endocrinology 16 903-911.

Fagin JA 2004 Challenging dogma in thyroid cancer molecular genetics-role of RET/PTC and BRAF in tumor initiation. Journal of Clinical Endocrinology and Metabolism 89 4264-4266.

Fenton CL, Lukes Y, Nicholson D, Dinauer CA, Francis GL \& Tuttle RM 2000 The RET/PTC mutations are common in sporadic papillary thyroid carcinoma of children and young adults. Journal of Clinical Endocrinology and Metabolism 85 1170-1175.

Franc B 2003 Observer variation of lesions of the thyroid. American Journal of Surgical Pathology 27 1177-1179.

Frattini M, Ferrario C, Bressan P, Balestra D, De Cecco L, Mondellini P, Bongarzone I, Collini P, Gariboldi M, Pilotti S et al. 2004 Alternative mutations of BRAF, RET 
and NTRK1 are associated with similar but distinct gene expression patterns in papillary thyroid cancer. Oncogene 23 7436-7740.

Fugazzola L, Pilotti S, Pinchera A, Vorontsova TV, Mondellini P, Bongarzone I, Greco A, Astakhova L, Butti MG, Demidchik EP et al. 1995 Oncogenic rearrangements of the RET proto-oncogene in papillary thyroid carcinomas from children exposed to the Chernobyl nuclear accident. Cancer Research 55 5617-5620.

Fugazzola L, Mannavola D, Cirello V, Vannucchi G, Muzza M, Vicentini L \& Beck-Peccoz P 2004 BRAF mutations in an Italian cohort of thyroid cancers. Clinical Endocrinology (Oxford) 61 239-243.

Fukushima T, Suzuki S, Mashiko M, Ohtake T, Endo Y, Takebayashi Y, Sekikawa K, Hagiwara K \& Takenoshita S 2003 BRAF mutations in papillary carcinomas of the thyroid. Oncogene 22 6455-6457.

Fusco A, Viglietto G \& Santoro M 2005 A new mechanism of BRAF activation in human thyroid papillary carcinomas. Journal of Clinical Investigation 115 20-23.

Garnett MJ \& Marais R 2004 Guilty as charged: BRAF is a human oncogene. Cancer Cell 6 313-319.

Gharib H, Goellner JR, Zinsmeister AR, Grant CS \& Van Heerden JA 1984 Fine-needle aspiration biopsy of the thyroid. The problem of suspicious cytologic findings. Annals of Internal Medicine 101 25-28.

Gire V, Marshall C \& Wynford-Thomas D 2000 PI-3-kinase is an essential anti-apoptotic effector in the proliferative response of primary human epithelial cells to mutant RAS. Oncogene 19 2269-2276.

Goldenberg D, Rosenbaum E, Argani P, Wistuba II, Sidransky D, Thuluvath PJ, Hidalgo M, Califano J \& Maitra A 2004 The V599E BRAF mutation is uncommon in biliary tract cancers. Modern Pathology 17 1386-1391.

Greaves TS, Olvera M, Florentine BD, Raza AS, Cobb CJ, Tsao-Wei DD, Groshen S, Singer P, Lopresti J \& Martin SE 2000 Follicular lesions of thyroid: a 5-year fine-needle aspiration experience. Cancer 90 335-341.

Hayashida N, Namba H, Kumagai A, Hayashi T, Ohtsuru A, Ito M, Saenko VA, Maeda S, Kanematsu T \& Yamashita S 2004 A rapid and simple detection method for the $B R A F(\mathrm{~T} 1796 \mathrm{~A})$ mutation in fine-needle aspirated thyroid carcinoma cells. Thyroid 14 910-915.

Hegedus L 2004 Clinical practice. The thyroid nodule. New England Journal of Medicine 351 1764-1771.

Hilger RA, Scheulen ME \& Strumberg D 2002 The Ras-Raf-MEK-ERK pathway in the treatment of cancer. Onkologie 25 511-518.

Hubbard SR 2004 Oncogenic mutations in B-Raf: some losses yield gains. Cell 116 764-766.

Hundahl SA, Fleming ID, Fremgen AM \& Menck HR 1998 A National Cancer Data Base report on 53,856 cases of thyroid carcinoma treated in the U.S., 1985-1995. Cancer 83 2638-2648.

Ichihara M, Murakumo Y \& Takahashi M 2004 RET and neuroendocrine tumors. Cancer Letters 204 197-211.
Ito T, Seyama T, Iwamoto KS, Hayashi T, Mizuno T, Tsuyama N, Dohi K, Nakamura N \& Akiyama M 1993 In vitro irradiation is able to cause RET oncogene rearrangement. Cancer Research 53 2940-2943.

Ito T, Seyama T, Iwamoto KS, Mizuno T, Tronko ND, Komissarenko IV, Cherstovoy ED, Satow Y, Takeichi N, Dohi K et al. 1994 Activated RET oncogene in thyroid cancers of children from areas contaminated by Chernobyl accident. Lancet 344259.

Jarry A, Masson D, Cassagnau E, Parois S, Laboisse C \& Denis MG 2004 Real-time allele-specific amplification for sensitive detection of the BRAF mutation V600E. Molecular and Cellular Probes 18 349-352.

Jhiang SM, Sagartz JE, Tong Q, Parker-Thornburg J, Capen CC, Cho JY, Xing S \& Ledent C 1996 Targeted expression of the ret/PTC1 oncogene induces papillary thyroid carcinomas. Endocrinology 137 375-378.

Jhiang SM, Cho JY, Furminger TL, Sagartz JE, Tong Q, Capen CC \& Mazzaferri EL 1998 Thyroid carcinomas in RET/PTC transgenic mice. Recent Results. Cancer Research 154 265-270.

Karasarides M, Chiloeches A, Hayward R, Niculescu-Duvaz D, Scanlon I, Friedlos F, Ogilvie L, Hedley D, Martin J, Marshall CJ et al. 2004 B-RAF is a therapeutic target in melanoma. Oncogene 23 6292-6298.

Kazakov VS, Demidchik EP \& Astakhova LN 1992 Thyroid cancer after Chernobyl. Nature 35921.

Kim DW, Hwang JH, Suh JM, Kim H, Song JH, Hwang ES, Hwang IY, Park KC, Chung HK, Kim JM et al. 2003 RET/PTC (rearranged in transformation/papillary thyroid carcinomas) tyrosine kinase phosphorylates and activates phosphoinositide-dependent kinase 1 (PDK1): an alternative phosphatidylinositol 3-kinase-independent pathway to activate PDK1. Molecular Endocrinology 17 1382-1394.

Kim KH, Kang DW, Kim SH, Seong IO \& Kang DY 2004 Mutations of the BRAF gene in papillary thyroid carcinoma in a Korean population. Yonsei Medical Journal 45 818-821.

Kimura ET, Nikiforova MN, Zhu Z, Knauf JA, Nikiforov YE \& Fagin JA 2003 High prevalence of BRAF mutations in thyroid cancer: genetic evidence for constitutive activation of the RET/PTC-RAS-BRAF signaling pathway in papillary thyroid carcinoma. Cancer Research 63 1454-1457.

Kimura ET, Vanvooren V, van Sande J, Nikiforov YE \& Fagin JA 2004 Autonomously functioning thyroid nodules are not associated with BRAF mutations. Clinical Endocrinology (Oxford) 60 394-396.

Klugbauer S, Lengfelder E, Demidchik EP \& Rabes HM 1995 High prevalence of RET rearrangement in thyroid tumors of children from Belarus after the Chernobyl reactor accident. Oncogene 11 2459-2467.

Knauf JA, Kuroda H, Basu S \& Fagin JA 2003 RET/PTCinduced dedifferentiation of thyroid cells is mediated through Y1062 signaling through SHC-RAS-MAP kinase. Oncogene 22 4406-4412. 
Knauf JA, Ma X, Smith EP, Zhang L, Mitsutake N, Nikiforov YE \& Fagin JA 2004 Targeted expression of BRAF $^{\mathrm{V} 600 \mathrm{E}}$ in thryoid cells of transgenic mice results in papillary thyroid cancers that transition to undifferentiated carcinomas. The 76th American Thyroid Association Annual Meeting, Vancouver, British Columbia, Canada. Abstract, short-call program \#2.

Koper JW \& Lamberts SW 2000 Sporadic endocrine tumours and their relationship to the hereditary endocrine neoplasia syndromes. European Journal of Clinical Investigation 30 493-500.

Krohn K \& Paschke R 2004 BRAF mutations are not an alternative explanation for the molecular etiology of ras-mutation negative cold thyroid nodules. Thyroid $\mathbf{1 4}$ 359-361.

Kroll TG, Sarraf P, Pecciarini L, Chen CJ, Mueller E, Spiegelman BM \& Fletcher JA 2000 PAX8PPARgammal fusion oncogene in human thyroid carcinoma. Science 289 1357-1360.

Kumagai A, Namba H, Saenko VA, Ashizawa K, Ohtsuru A, Ito M, Ishikawa $\mathrm{N}$, Sugino K, Ito K, Jeremiah $\mathrm{S}$ et al. 2004 Low frequency of BRAFT1796A mutations in childhood thyroid carcinomas. Journal of Clinical Endocrinology Metabolism 89 4280-4284.

Kumar R, Angelini S, Czene K, Sauroja I, HahkaKemppinen M, Pyrhonen S \& Hemminki K 2003 BRAF mutations in metastatic melanoma: a possible association with clinical outcome. Clinical Cancer Research 9 3362-3368.

Kumar MS, Moore KE \& Brose MS 2004 Functional analysis of BRAF in a papillary thyroid cancer cell line. Thyroid 14712.

Lee JT \& McCubrey JA 2003 BAY-43-9006. Bayer/Onyx. Current Opinion in Investigative Drugs 4 757-763.

Lilleberg SL, Durocher J, Sanders C, Walters K \& Culver K 2004 High sensitivity scanning of colorectal tumors and matched plasma DNA for mutations in APC, TP53, KRAS, and BRAF genes with a novel DHPLC fluorescence detection platform. Annals of the New York Academy of Sciences 1022 250-256.

Lima J, Trovisco V, Soares P, Maximo V, Magalhaes J, Salvatore G, Santoro M, Bogdanova T, Tronko M, Abrosimov A et al. 2004 BRAF mutations are not a major event in post-Chernobyl childhood thyroid carcinomas. Journal of Clinical Endocrinology and Metabolism 89 4267-4271.

Lloyd RV, Erickson LA, Casey MB, Lam KY, Lohse CM, Asa SL, Chan JK, DeLellis RA, Harach HR, Kakudo K et al. 2004 Observer variation in the diagnosis of follicular variant of papillary thyroid carcinoma. American Journal of Surgical Pathology 28 1336-1340.

McIver B, Grebe SK \& Eberhardt NL 2004 The PAX8/ PPARgamma fusion oncogene as a potential therapeutic target in follicular thyroid carcinoma. Current Drug Targets. Immune, Endocrine and Metabolic Disorders 4 221-234.
Mercer KE \& Pritchard CA 2003 Raf proteins and cancer: B-Raf is identified as a mutational target. Biochimica et Biophysica Acta 1653 25-40.

Merino MJ \& Monteagudo C 1997 Tall cell carcinoma of the thryoid: an aggressive variant of papillary cancer. Pathology Case Reviews 2 196-199.

Miyagi E, Braga-Basaria M, Hardy E, Vasko V, Burman K D, Jhiang S, Saji M \& Ringel MD 2004 Chronic expression of RET/PTC 3 enhances basal and insulinstimulated PI3 kinase/AKT signaling and increases IRS-2 expression in FRTL-5 thyroid cells. Molecular Carcinogenesis 41 98-107.

Mizuno T, Kyoizumi S, Suzuki T, Iwamoto KS \& Seyama T 1997 Continued expression of a tissue specific activated oncogene in the early steps of radiation-induced human thyroid carcinogenesis. Oncogene 15 1455-1460.

Namba H, Nakashima M, Hayashi T, Hayashida N, Maeda S, Rogounovitch TI, Ohtsuru A, Saenko VA, Kanematsu T \& Yamashita S 2003 Clinical Implication of hot spot BRAF mutation, V599E, in papillary thyroid cancers. Journal of Clinical Endocrinology and Metabolism $\mathbf{8 8}$ 4393-4397.

Nikiforov YE $2002 R E T / P T C$ rearrangement in thyroid tumors. Endocrine Pathology 13 3-16.

Nikiforov YE, Rowland JM, Bove KE, Monforte-Munoz H \& Fagin JA 1997 Distinct pattern of ret oncogene rearrangements in morphological variants of radiationinduced and sporadic thyroid papillary carcinomas in children. Cancer Research 57 1690-1694.

Nikiforova MN, Kimura ET, Gandhi M, Biddinger PW, Knauf JA, Basolo F, Zhu Z, Giannini R, Salvatore G, Fusco A et al. 2003 BRAF mutations in thyroid tumors are restricted to papillary carcinomas and anaplastic or poorly differentiated carcinomas arising from papillary carcinomas. Journal of Clinical Endocrinology and Metabolism 88 5399-5404.

Nikiforova MN, Ciampi R, Salvatore G, Santoro M, Gandhi M, Knauf JA, Thomas GA, Jeremiah S, Bogdanova TI, Tronko MD et al. 2004 Low prevalence of BRAF mutations in radiation-induced thyroid tumors in contrast to sporadic papillary carcinomas. Cancer Letters 209 1-6.

Nilsson M 2001 Iodide handling by the thyroid epithelial cell. Experimental \& Clinical Endocrinology and Diabetes 109 13-17.

Omholt K, Platz A, Kanter L, Ringborg U \& Hansson J 2003 NRAS and BRAF mutations arise early during melanoma pathogenesis and are preserved throughout tumor progression. Clinical Cancer Research 9 6483-6488.

Penko KS, Livezey J, Fenton CL, Patel A, Nicholson D, Flores M, Oakley K, Tuttle RM \& Francis GL 2004 BRAF mutations are less common in childhood papillary thyroid cancer (PTC) than adult PTC. Thyroid $\mathbf{1 4} 750$.

Perren A, Schmid S, Locher T, Saremaslani P, Bonvin C, Heitz PU \& Komminoth P 2004 BRAF and endocrine tumors: mutations are frequent in papillary thyroid 
carcinomas, rare in endocrine tumors of the gastrointestinal tract and not detected in other endocrine tumors. Endocrine-Related Cancer 11 855-860.

Peyssonnaux C \& Eychene A 2001 The Raf/MEK/ERK pathway: new concepts of activation. Biology of the Cell 93 53-62.

Pfeifer GP, Yoon JH, Liu L, Tommasi S, Wilczynski SP \& Dammann R 2002 Methylation of the RASSF1A gene in human cancers. Biological Chemistry 383 907-914.

Pollock PM, Harper UL, Hansen KS, Yudt LM, Stark M, Robbins CM, Moses TY, Hostetter G, Wagner U, Kakareka J et al. 2003 High frequency of BRAF mutations in nevi. Nature Genetics 33 19-20.

Powell DJ Jr, Russell J, Nibu K, Li G, Rhee E, Liao M, Goldstein M, Keane WM, Santoro M, Fusco A et al. 1998 The RET/PTC3 oncogene: metastatic solid-type papillary carcinomas in murine thyroids. Cancer Research $\mathbf{5 8}$ 5523-5528.

Prendiville S, Burman KD, Ringel MD, Shmookler BM, Deeb ZE, Wolfe K, Azumi N, Wartofsky L \& Sessions RB 2000 Tall cell variant: an aggressive form of papillary thyroid carcinoma. Otolaryngology Head and Neck Surgery 122 352-357.

Puxeddu E, Moretti S, Elisei R, Romei C, Pascucci R, Martinelli M, Marino C, Avenia N, Rossi ED, Fadda G et al. 2004 BRAF(V599E) mutation is the leading genetic event in adult sporadic papillary thyroid carcinomas. Journal of Clinical Endocrinology and Metabolism 89 2414-2420.

Rajagopalan H, Bardelli A, Lengauer C, Kinzler KW, Vogelstein B \& Velculescu VE 2002 Tumorigenesis: RAF/ RAS oncogenes and mismatch-repair status. Nature 418 934.

Rinehart J, Adjei AA, Lorusso PM, Waterhouse D, Hecht JR, Natale RB, Hamid O, Varterasian M, Asbury P, Kaldjian EP et al. 2004 Multicenter phase II study of the oral MEK inhibitor, CI-1040, in patients with advanced non-small-cell lung, breast, colon, and pancreatic cancer. Journal of Clinical Oncology 22 4456-4462.

Rosenberg AM, Cradic KW, Sekulic A, Mai M, Pittelkow MR, Halling KC, Erickson LA, Hay ID, Eberhardt NL, McIver B et al. 2004 Detection of circulating BRAFmutant cell in papillary thyroid carcinoma. The Endocrine Society's 86th Annual Meeting, New Orleans, LA, USA. Abstract OR21-6.

Sahin M, Allard BL, Yates M, Powell JG, Wang XL, Hay ID, Zhao Y, Goellner JR, Sebo TJ, Grebe SK et al. 2005 PPARgamma staining as a surrogate for PAX8/ PPARgamma fusion oncogene expression in follicular neoplasms: clinico-pathologic correlation and histopathological diagnostic value. Journal of Clinical Endocrinology and Metabolism 90 463-468.

Salvatore G, Giannini R, Faviana P, Caleo A, Migliaccio I, Fagin JA, Nikiforov YE, Troncone G, Palombini L, Basolo F et al. 2004 Analysis of BRAF point mutation and RET/PTC rearrangement refines the fine-needle aspiration diagnosis of papillary thyroid carcinoma.
Journal of Clinical Endocrinology and Metabolism 89 5175-5180.

Santoro M, Chiappetta G, Cerrato A, Salvatore D, Zhang L, Manzo G, Picone A, Portella G, Santelli G, Vecchio G et al. 1996 Development of thyroid papillary carcinomas secondary to tissue-specific expression of the RET/PTC1 oncogene in transgenic mice. Oncogene 12 1821-1826.

Santoro M, Melillo RM, Carlomagno F, Fusco A \& Vecchio G 2002 Molecular mechanisms of RET activation in human cancer. Annals of the New York Academy of Sciences 963 116-121.

Santoro M, Melillo RM, Carlomagno F, Vecchio G \& Fusco A 2004 Minireview: RET: normal and abnormal functions. Endocrinology 145 5448-5451.

Schagdarsurengin U, Gimm O, Hoang-Vu C, Dralle H, Pfeifer GP \& Dammann R 2002 Frequent epigenetic silencing of the $\mathrm{CpG}$ island promoter of RASSF1A in thyroid carcinoma. Cancer Research 62 3698-3701.

Sclabas GM, Staerkel GA, Shapiro SE, Fornage BD, Sherman SI, Vassillopoulou-Sellin R, Lee JE \& Evans DB 2003 Fine-needle aspiration of the thyroid and correlation with histopathology in a contemporary series of 240 patients. American Journal of Surgery 186 702-709.

Sebolt-Leopold JS 2004 MEK inhibitors: a therapeutic approach to targeting the Ras-MAP kinase pathway in tumors. Current Pharmaceutical Design 10 1907-1914.

Sedliarou I, Saenko V, Lantsov D, Rogounovitch T, Namba H, Abrosimov A, Lushnikov E, Kumagai A, Nakashima M, Meirmanov S et al. 2004 The BRAFT1796A transversion is a prevalent mutational event in human thyroid microcarcinoma. International Journal of Oncology 25 1729-1735.

Sherman SI 2003 Thyroid carcinoma. Lancet 361 501-511.

Shore RE, Woodard E, Hildreth N, Dvoretsky P, Hempelmann L \& Pasternack B 1985 Thyroid tumors following thymus irradiation. Journal of National Cancer Institute 74 1177-1184.

Singer G, Oldt R 3rd, Cohen Y, Wang BG, Sidransky D, Kurman RJ \& Shih IeM 2003 Mutations in BRAF and KRAS characterize the development of low-grade ovarian serous carcinoma. Journal of National Cancer Institute $\mathbf{9 5}$ 484-486.

Sithanandam G, Druck T, Cannizzaro LA, Leuzzi G, Huebner K \& Rapp UR 1992 B-raf and a B-raf pseudogene are located on $7 \mathrm{q}$ in man. Oncogene 7 795-799.

Soares P, Trovisco V, Rocha AS, Lima J, Castro P, Preto A, Maximo V, Botelho T, Seruca R \& Sobrinho-Simoes M 2003 BRAF mutations and RET/PTC rearrangements are alternative events in the etiopathogenesis of PTC. Oncogene 22 4578-4580.

Soares P, Trovisco V, Rocha AS, Feijao T, Rebocho AP, Fonseca E, Vieira de Castro I, Cameselle-Teijeiro J, Cardoso-Oliveira M \& Sobrinho-Simoes M 2004 BRAF mutations typical of papillary thyroid carcinoma are more 
frequently detected in undifferentiated than in insular and insular-like poorly differentiated carcinomas. Virchows Archiv 444 572-576.

Tallini G 2002 Molecular pathobiology of thyroid neoplasms. Endocrine Pathology 13 271-288.

Trovisco V, Vieira de Castro I, Soares P, Maximo V, Silva P, Magalhaes J, Abrosimov A, Guiu XM \& SobrinhoSimoes M 2004 BRAF mutations are associated with some histological types of papillary thyroid carcinoma. Journal of Pathology 202 247-251.

Unger K, Zitzelsberger H, Salvatore G, Santoro M, Bogdanova T, Braselmann H, Kastner P, Zurnadzhy L, Tronko N, Hutzler P et al. 2004 Heterogeneity in the distribution of RET/PTC rearrangements within individual post-Chernobyl papillary thyroid carcinomas. Journal of Clinical Endocrinology and Metabolism 89 4272-4279.

Vander JB, Gaston EA \& Dawber TR 1968 The significance of nontoxic thyroid nodules. Final report of a 15-year study of the incidence of thyroid malignancy. Annals of Internal Medicine 69 537-540.

Vasil'ev EV, Roumiantsev PO, Saenko VA, Il'in AA, Polyakova EY, Nemtsova MV \& Zaletayev DV 2004 Molecular analysis of structural abnormalities in papillary thyroid carcinoma gene. Molecular Biology (Moscow) 38 642-653.

Vasko V, Ferrand M, Di Cristofaro J, Carayon P, Henry JF \& de Micco C 2003 Specific pattern of RAS oncogene mutations in follicular thyroid tumors. Journal of Clinical Endocrinology and Metabolism $\mathbf{8 8}$ 2745-2752.

Vdovichenko KK, Markova SI \& Belokhvostov AS 2004 Mutant form of BRAF gene in blood plasma of cancer patients. Annals of the New York Academy of Sciences 1022 228-231.

Venkataraman GM, Yatin M, Marcinek R \& Ain KB 1999 Restoration of iodide uptake in dedifferentiated thyroid carcinoma: relationship to human $\mathrm{Na}+/$ I-symporter gene methylation status. Journal of Clinical Endocrinology and Metabolism 84 2449-2457.

Vos MD, Ellis CA, Bell A, Birrer MJ \& Clark GJ 2000 Ras uses the novel tumor suppressor RASSF1 as an effector to mediate apoptosis. Journal of Biological Chemistry 275 35669-35672.

Wan PT, Garnett MJ, Roe SM, Lee S, Niculescu-Duvaz D, Good VM, Jones CM, Marshall CJ, Springer CJ, Barford D et al. 2004 Mechanism of activation of the RAF-ERK signaling pathway by oncogenic mutations of B-RAF. Cell 116 855-867.

Werk EE Jr, Vernon BM, Gonzalez JJ, Ungaro PC \& McCoy RC 1984 Cancer in thyroid nodules. A community hospital survey. Archives of Internal Medicine $\mathbf{1 4 4}$ 474-476.

Wilhelm S \& Chien DS 2002 BAY 43-9006 colon; preclinical data. Current Pharmaceutical Design 8 2255-2257.

Wilhelm SM, Carter C, Tang L, Wilkie D, McNabola A, Rong H, Chen C, Zhang X, Vincent P, McHugh M et al. 2004 BAY 43-9006 exhibits broad spectrum oral antitumor activity and targets the RAF/MEK/ERK pathway and receptor tyrosine kinases involved in tumor progression and angiogenesis. Cancer Research 64 7099-7109.

Wood JW, Tamagaki H, Neriishi S, Sato T, Sheldon WF, Archer PG, Hamilton HB \& Johnson KG 1969 Thyroid carcinoma in atomic bomb survivors Hiroshima and Nagasaki. American Journal of Epidemiology 89 4-14.

Xing M, Usadel H, Cohen Y, Tokumaru Y, Guo Z, Westra WB, Tong BC, Tallini G, Udelsman R, Califano JA et al. $2003 a$ Methylation of the thyroid-stimulating hormone receptor gene in epithelial thyroid tumors: a marker of malignancy and a cause of gene silencing. Cancer Research 63 2316-2321.

Xing M, Tokumaru Y, Wu G, Westra WB, Ladenson PW \& Sidransky D 2003b Hypermethylation of the Pendred syndrome gene SLC26A4 is an early event in thyroid tumorigenesis. Cancer Research 63 2312-2315.

Xing M, Cohen Y, Mambo E, Tallini G, Udelsman R, Ladenson PW \& Sidransky D $2004 a$ Early occurrence of RASSF1A hypermethylation and its mutual exclusion with $B R A F$ mutation in thyroid tumorigenesis. Cancer Research 64 1664-1668.

Xing M, Vasko V, Tallini G, Larin A, Wu G, Udelsman R, Ringel MD, Ladenson PW \& Sidransky D 2004b BRAF T1796A transversion mutation in various thyroid neoplasms. Journal of Clinical Endocrinology and Metabolism 89 1365-1368.

Xing M, Tufano RP, Tufaro AP, Basaria S, Ewertz M, Rosenbaum E, Byrne PJ, Wang J, Sidransky D \& Ladenson PW 2004c Detection of BRAF mutation on fine needle aspiration biopsy specimens: a new diagnostic tool for papillary thyroid cancer. Journal of Clinical Endocrinology and Metabolism 89 2867-2872.

Xu X, Quiros RM, Gattuso P, Ain KB \& Prinz RA 2003 High prevalence of BRAF gene mutation in papillary thyroid carcinomas and thyroid tumor cell lines. Cancer Research 63 4561-4567.

Zhu Z, Gandhi M, Nikiforova MN, Fischer AH \& Nikiforov YE 2003 Molecular profile and clinical-pathologic features of the follicular variant of papillary thyroid carcinoma. An unusually high prevalence of ras mutations. American Journal of Clinical Pathology 120 71-77. 